\title{
Tetralogy of Fallot and atrial septal defect in a white Bengal Tiger cub (Panthera tigris tigris)
}

\author{
Paolo Pazzi ${ }^{1 *}$, Chee K Lim ${ }^{2,3}$ and Johan Steyl ${ }^{4}$
}

\begin{abstract}
A 3-week-old female white Bengal Tiger cub (Panthera tigris tigris) presented with acute onset tachypnoea, cyanosis and hypothermia. The cub was severely hypoxaemic with a mixed acid-base disturbance. Echocardiography revealed severe pulmonic stenosis, right ventricular hypertrophy, high membranous ventricular septal defect and an overriding aorta. Additionally, an atrial septal defect was found on necropsy, resulting in the final diagnosis of Tetralogy of Fallot with an atrial septal defect (a subclass of Pentalogy of Fallot). This report is the first to encompass arterial blood gas analysis, thoracic radiographs, echocardiography and necropsy findings in a white Bengal Tiger cub diagnosed with Tetralogy of Fallot with an atrial septal defect.
\end{abstract}

Keywords: Pentalogy, Pulmonic stenosis, Echocardiography, Necropsy

\section{Background}

Tetralogy of Fallot (TOF) is a rare and complex congenital cardiac disorder characterised by ventricular septal defect (VSD), right ventricular outflow tract narrowing or obstruction (pulmonic stenosis [PS]), overriding aorta and secondary hypertrophy of the right ventricle. TOF has been reported in dogs [1,2], cats [3-5], horses [6], cattle [7], sheep [8], an European beaver [9], a Japanese macaque [10], and an European brown bear [11]. The incidence of TOF in dogs diagnosed with congenital heart disease is approximately $0.6-1 \%[1,2]$ and the condition is considered even rarer in the cat with only a few case reports documented to date [3-5]. Pentalogy of Fallot (POF) is a rare variant of the relatively more common TOF, comprising the aforementioned four classic features of TOF with an additional atrial septal defect (ASD) or patent ductus arteriosus (PDA). POF has previously been described in three dogs [12-14], two horses $[15,16]$, a ram [17] and as a necropsy finding in a twoyear-old Siberian Tiger [18], however, of these reports, only a Korean Sapsaree dog [13] and the Siberian Tiger [17] have been diagnosed exclusively with TOF and an ASD.

\footnotetext{
* Correspondence: paolo.pazzi@up.ac.za

'Department of Companion Animal Clinical Studies, Faculty of Veterinary Science, University of Pretoria, Private Bag X04, Onderstepoort 0110, South Africa

Full list of author information is available at the end of the article
}

The haemodynamics of TOF depends largely on the degree of right ventricular outflow tract obstruction. The VSD is usually nonrestrictive and if right ventricular outflow obstruction is severe, the intracardiac shunt is from right to left and pulmonary blood flow may be markedly diminished with deoxygenated blood being pumped into circulation resulting in cyanosis. The right ventricular hypertrophy is secondary to the pressure overload created by the PS and impingement of the interventricular septum on the right ventricular outflow tract, rather than a primary embryological malformation.

This is the first description of TOF with ASD (a subclass of POF) to include arterial blood gas analysis, diagnostic imaging and necropsy findings in a white Bengal Tiger (Panthera tigris tigris).

\section{Case presentation}

A 3-week-old female white Bengal Tiger cub presented with a history of one day anorexia and tachypnoea. The cub suckled from the mother for one week, and was bottle fed thereafter. The cub was stunted and approximately half the size of her litter mates. On clinical examination the cub was in severe respiratory distress with increased expiratory effort, increased lung sounds with severe cyanosis of the mucous membranes. Although tachycardia was present (180 beats/minute), a murmur could not be detected most likely due to the expiratory lung noises. Mild hypothermia $\left(36.9^{\circ} \mathrm{C}\right.$, normal range: $\left.38.0-39.0^{\circ} \mathrm{C}\right)$ was also 
present. Initial management included oxygen supplementation and $0.1 \mathrm{mg} / \mathrm{kg}$ of butorphanol (V-Tech Pharmacy, Midrand, South Africa) intramuscularly, subsequently reducing the patient's respiratory distress and reducing the severity of cyanosis. Serum biochemistry and electrolytes revealed no significant abnormalities, arterial blood gas showed severe hypoxia - partial arterial pressure of oxygen: 27.1 (normal range: $75-100 \mathrm{mmHg}$ ), mild acidosis pH: 7.341 (normal range: 7.350-7.450), low bicarbonate 13.2 (normal range: $20-24 \mathrm{mmol} / \mathrm{L}$ ) and low partial arterial pressure of carbon dioxide $\left(\mathrm{p}_{\mathrm{a}} \mathrm{CO}_{2}\right): 20.9$ (normal range: $32.0-45.0 \mathrm{mmHg}$ ).

A prominent main pulmonary arterial bulge was seen superimposing over the aorta on the dorsoventral thoracic radiograph, corresponding with a soft tissue bulge at the cranial aspect of the base of the cardiac silhouette on the right lateral thoracic radiograph (Figure 1). There was a mild but inconsistent increased interstitial lung pattern seen in the cranial cupula and ventral aspect of the caudal lung lobes (seen only on lateral but not on dorsoventral view). The overall radiological findings were suggestive of pulmonic stenosis with post-stenotic main pulmonary artery dilatation and therefore, echocardiography was subsequently performed.

On the right parasternal long axis echocardiography view, moderate thickening of the right ventricular free wall (two times the thickness of the left ventricular free wall) and interventricular septum (1.5 times the thickness of the left ventricular free wall) was visible, indicating moderate right ventricular hypertrophy (Figure 2). Marked enlargement of the right atrium was noted with severe, turbulent high velocity trans-tricuspid regurgitation up to $559 \mathrm{~cm} / \mathrm{s}$ detected on continuous wave Doppler. On investigation of the left ventricular outflow tract, a high membranous ventricular septal defect (up to $2.4 \mathrm{~mm}$ wide) with concomitant overriding aorta was appreciable (Figure 3). A right-to-left ventricular shunt was detected on colour flow Doppler (Figure 4) with peak velocity up to $185 \mathrm{~cm} / \mathrm{s}$ on spectral Doppler, with the majority of the shunted blood directed towards the left ventricular outflow tract and subaortic region. On the right parasternal short axis view, severe subvalvular PS characterised by marked narrowing of the right ventricular outflow tract was seen with post-stenotic peak velocity of $565 \mathrm{~cm} / \mathrm{s}$ (Figure 5). Severe patient tachypnoea during the echocardiographic examination resulted in marked cardiac excursion and made it impossible to obtain an accurate M-mode tracing. Nevertheless, with the overall findings of high membranous VSD, overriding aorta, severe PS and right ventricular hypertrophy, a tentative diagnosis of TOF with a right-to-left VSD shunt was made.

Due to the severity of the condition and the poor prognosis the patient was euthanased and a necropsy conducted. The multiple echocardiographic findings were confirmed during macroscopic examination and included an overriding aorta associated with a subaortic VSD, concentric right ventricular hypertrophy and right atrial dilatation, subpulmonary stenosis associated with localised ventricular septal hypertrophy resulting in pulmonary valve and trunk hypoplasia and aortic trunk dilatation. In addition, an ASD, consistent with an ostium secundum was found (Figures 6, 7, 8, and 9). The caudal thoracic periaortic mediastinum exhibited multiple prominent small tortuous blood filled vessels (veins) extending between the azygos - and costal veins and dorsocaudal pulmonary pleura (Figure 10). Prominent coronary veins due to marked venous dilatation could also be detected macroscopically.

No significant histopathological changes on routine haematoxylin \& eosin staining could be demonstrated in
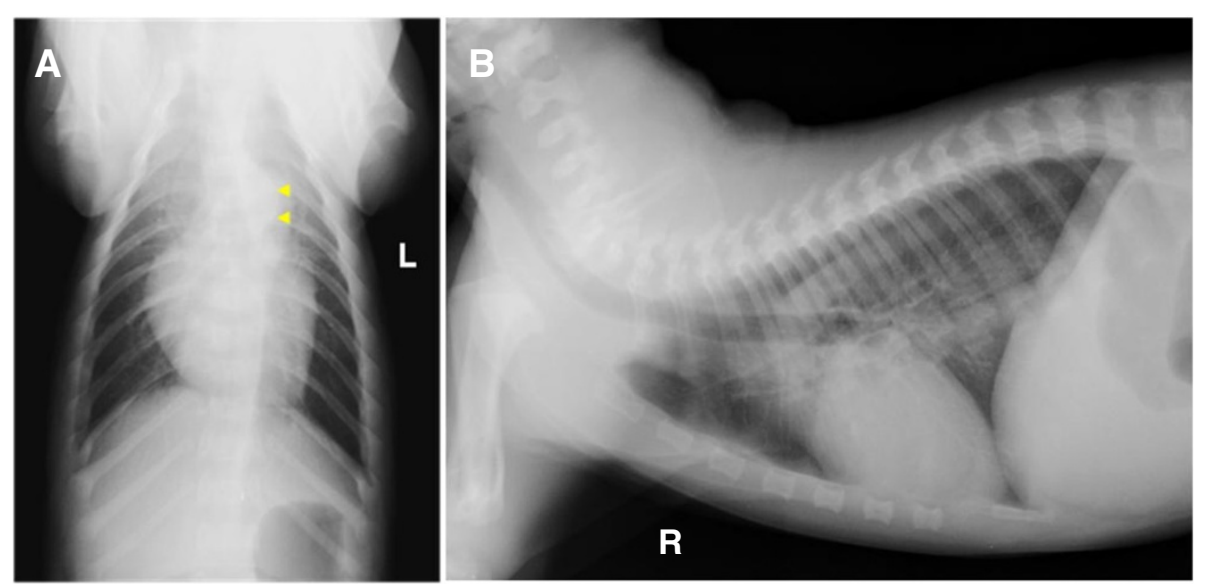

Figure 1 Dorsoventral (A) and right lateral (B) thoracic radiographs. Prominent main pulmonary artery bulge seen superimposing over the descending aorta on dorsoventral view and corresponding to soft tissue opacity at the cranial aspect of the heart base on the orthogonal view. Arrow heads point at the bulge in the pulmonary artery. 


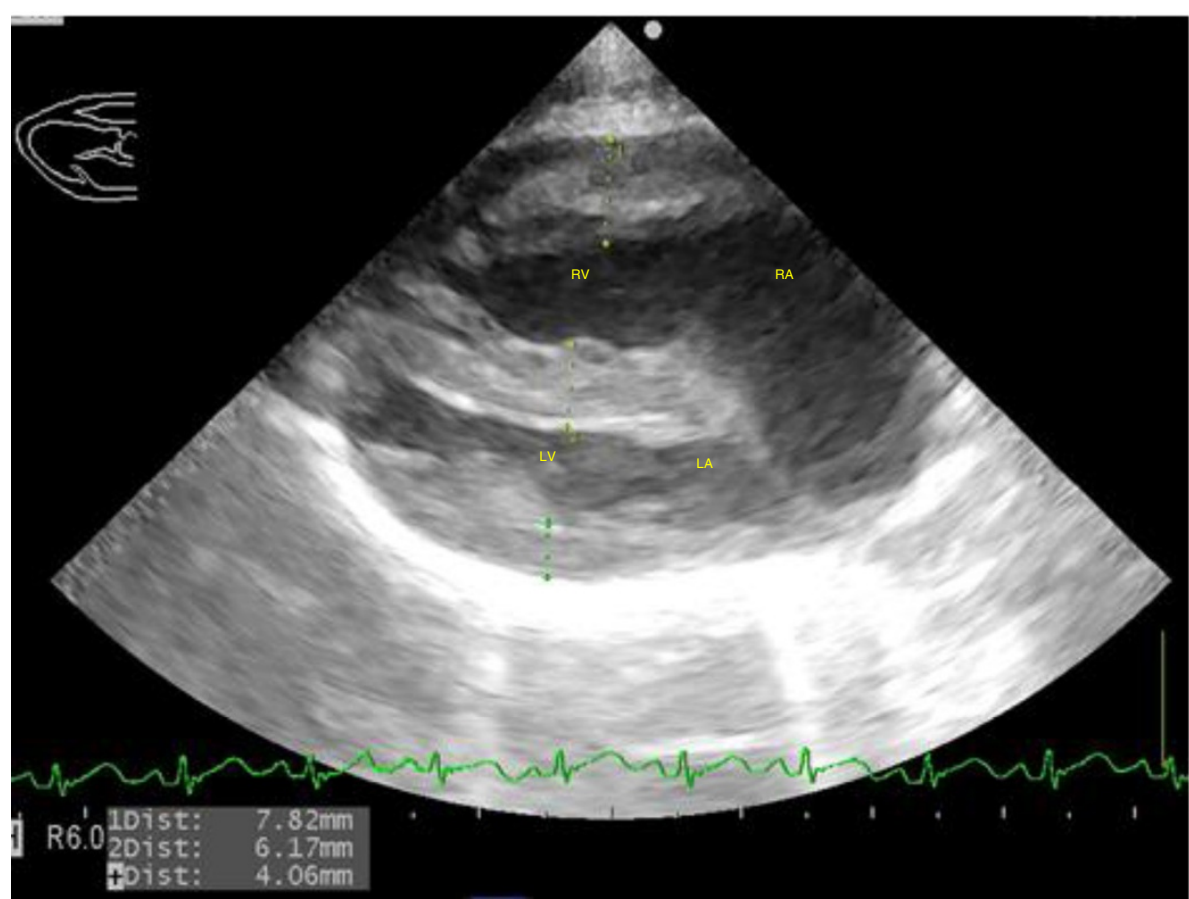

Figure 2 Right parasternal long axis view of the heart with severe right atrial enlargement and moderate right ventricular hypertrophy. Note the thickening of the right ventricular free wall and interventricular septum. Right atrium (RA), right ventricle (RV), left atrium (LA), left ventricle (LV).

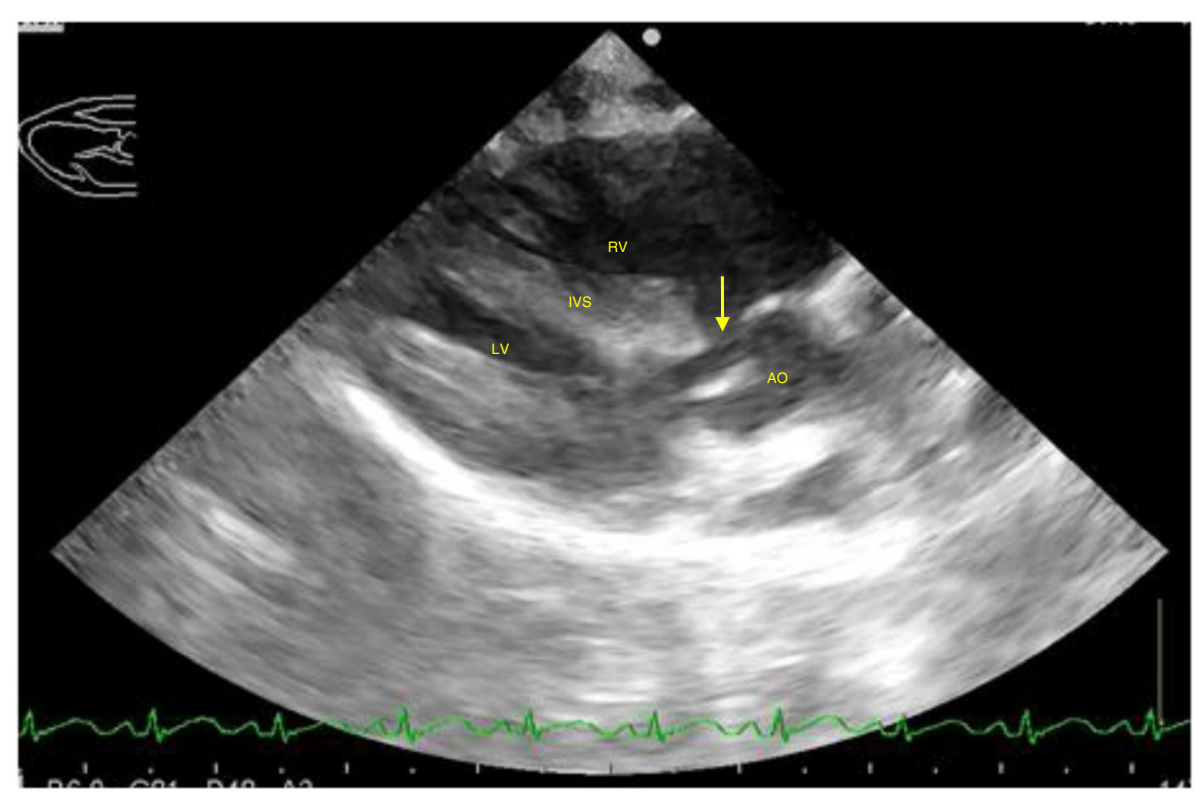

Figure 3 Right parasternal long axis left ventricular outflow tract view of the heart with ventricular septal defect and overriding aorta. A high membranous ventricular septal defect (arrow) is visible at the subaortic region. Right atrium (RA), right ventricle (RV), left atrium (LA), left ventricle (LV), interventricular septum (IVS). 


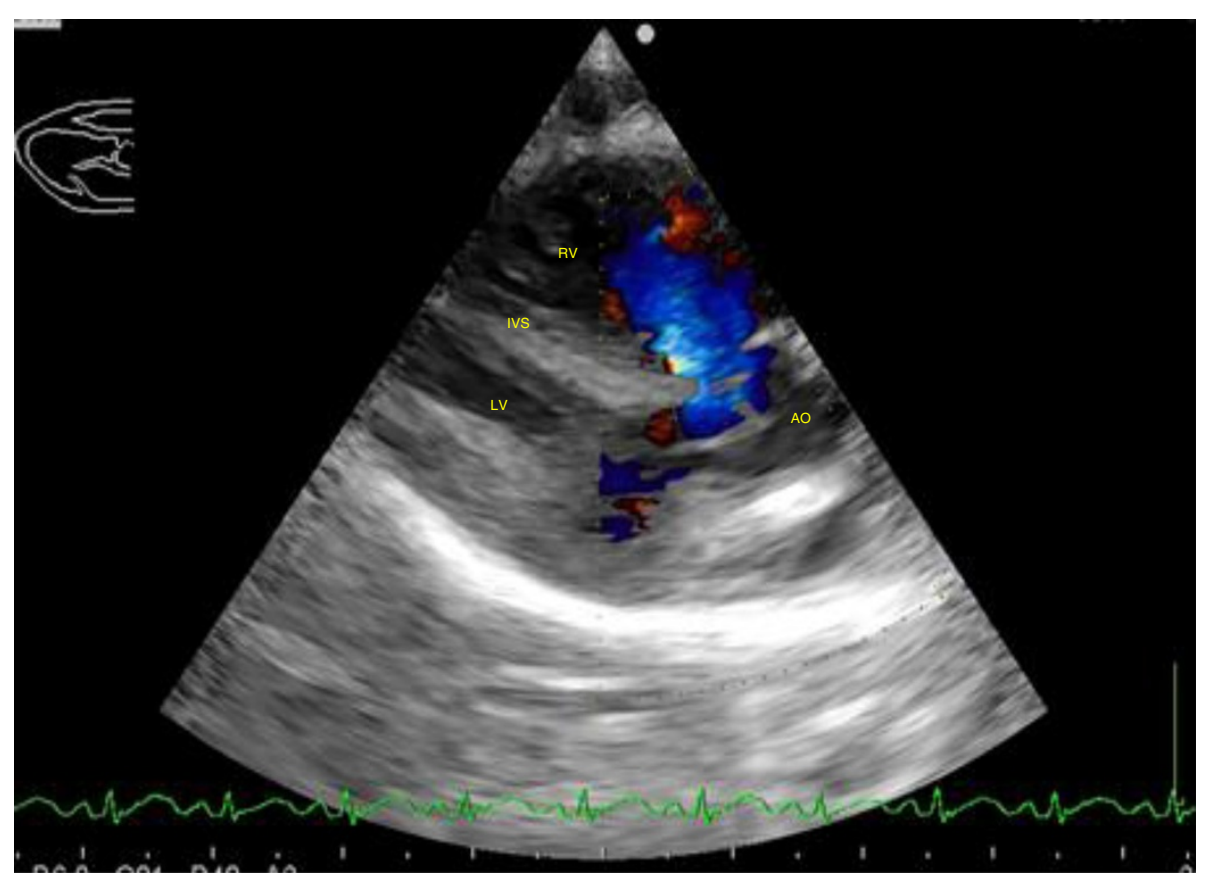

Figure 4 Right parasternal long axis left ventricular outflow tract view of the heart with colour flow Doppler with a reversed ventricular septal defect shunt. A right to left shunt characterised by blue-colour flow across the high membranous ventricular septal defect with concomitant overriding aorta. Right atrium (RA), right ventricle (RV), left atrium (LA), left ventricle (LV), interventricular septum (IVS).

myocardial fibres. Marked coronary vein dilatation histologically supported the macroscopic observation. The lungs showed generalised alveolar micro-atelectasis associated with pulmonary arterial collapse and hypoplasia due to poor pulmonary arterial perfusion. The bronchial and terminal bronchiolar veins were generally significantly distended. Histologically, the caudodorsal pulmonary pleural findings supported the macroscopic observation of prominent venous dilatation in pleural adventitia. Of other organs examined histologically, only

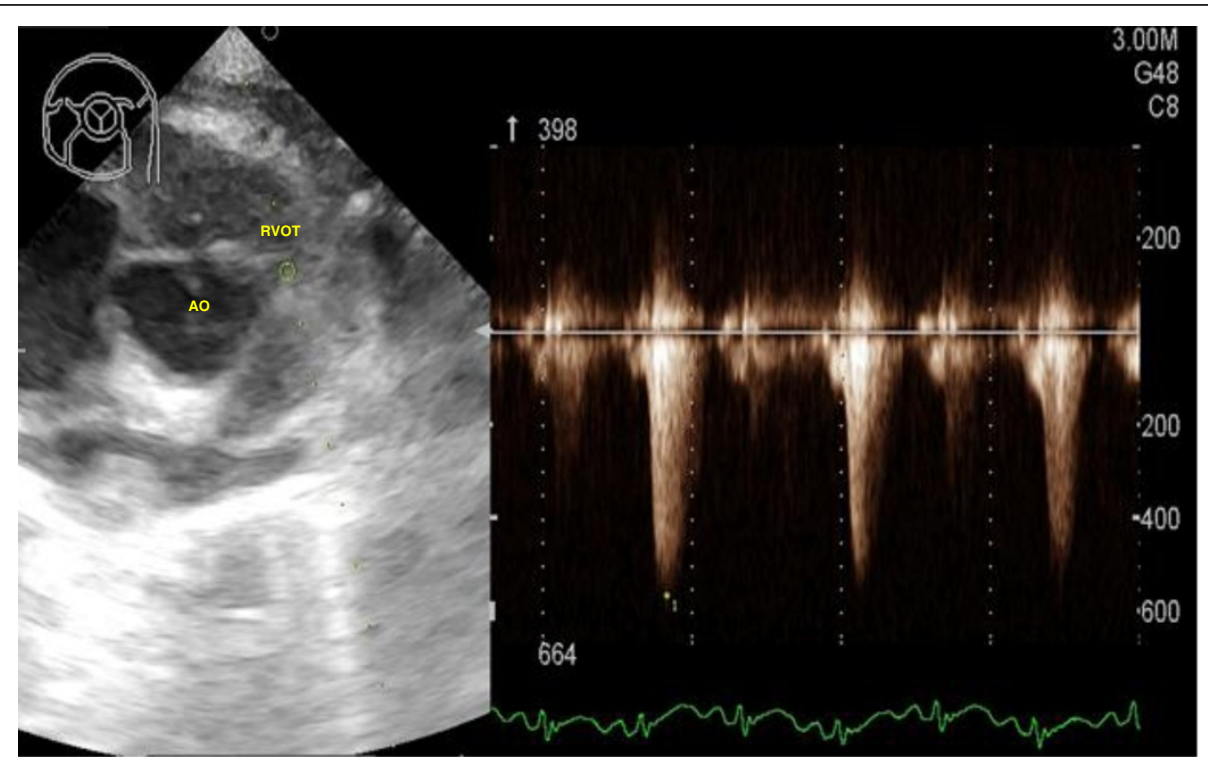

Figure 5 Right parasternal short axis view of the heart base with right ventricular outflow tract and continuous wave Doppler showing severe subvalvular pulmonic stenosis. There is marked narrowing of the right ventricular outflow tract with post-stenotic peak velocity of $564.5 \mathrm{~cm} / \mathrm{s}$. Right ventricular outflow tract (RVOT), aorta (AO). 


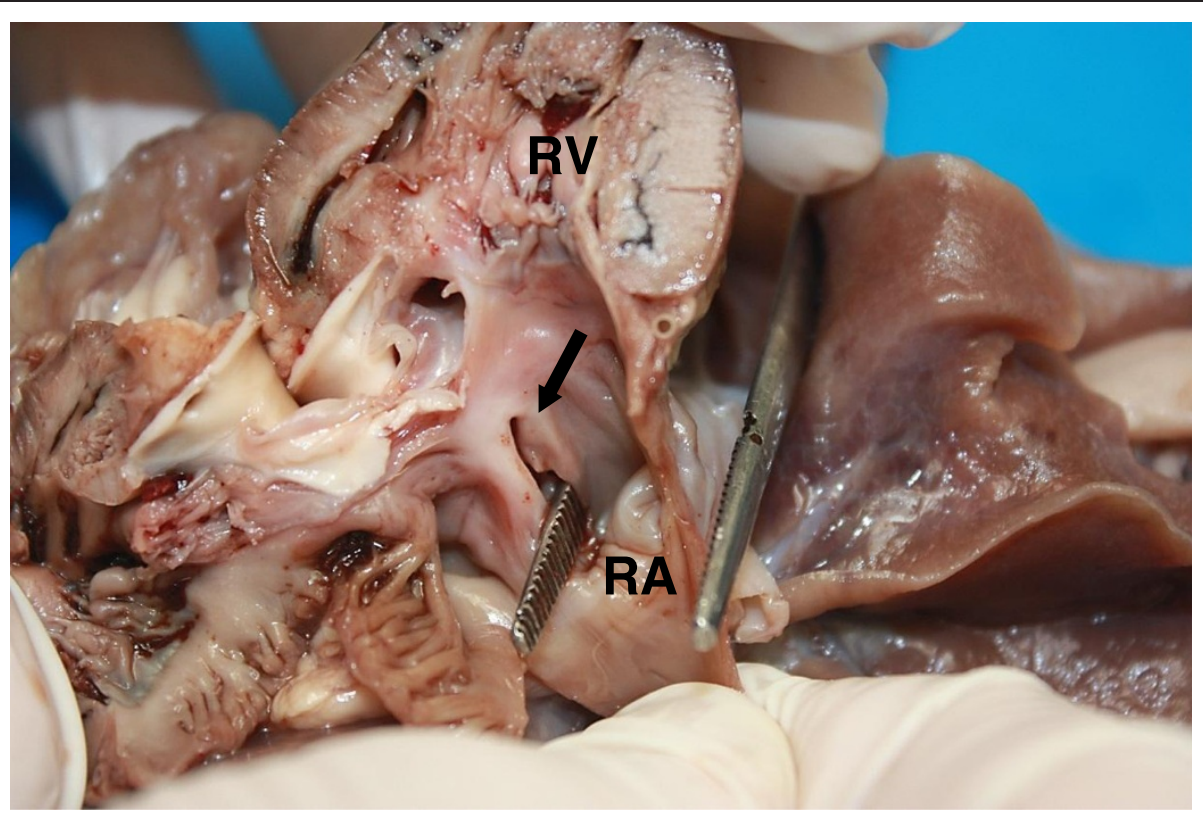

Figure 6 Sagittal section through the right ventricle (RV). There is an atrial septal defect (ostium secundum) between the right (RA) and left atrium (arrow and forceps). The right atrium is also significantly dilated.

the liver showed significant change, manifesting as moderate global hepatic venous dilatation.

\section{Discussion}

Tetralogy of Fallot results from abnormal embryonic development of the conotruncal septum, resulting in varying degrees of infundibular and valvular PS, pulmonary artery hypoplasia, malalignment of the infundibular septum, and a VSD [19]. Specific genetic associations with TOF in humans include alterations in JAG1 [20], NKX2-5 [21], ZFPM2 [22] and VEGF [23] while in dogs the inbreeding of Keeshond dogs led to the suspicion of a polygenetic threshold inheritance model for TOF $[24,25]$. Specific genetic associations have not been elucidated in dogs. Concurrent developmental abnormalities in addition to those causing TOF lead to ASD or PDA and resultant POF. TOF with ASD is a very rare condition and has been reported in only 2 animal species as sporadic individual case reports $[13,17]$. The white colour of Bengal Tigers is due to a recessive trait with selective inbreeding in captivity often encouraging the expression of recessive traits, and although TOF has not been associated with

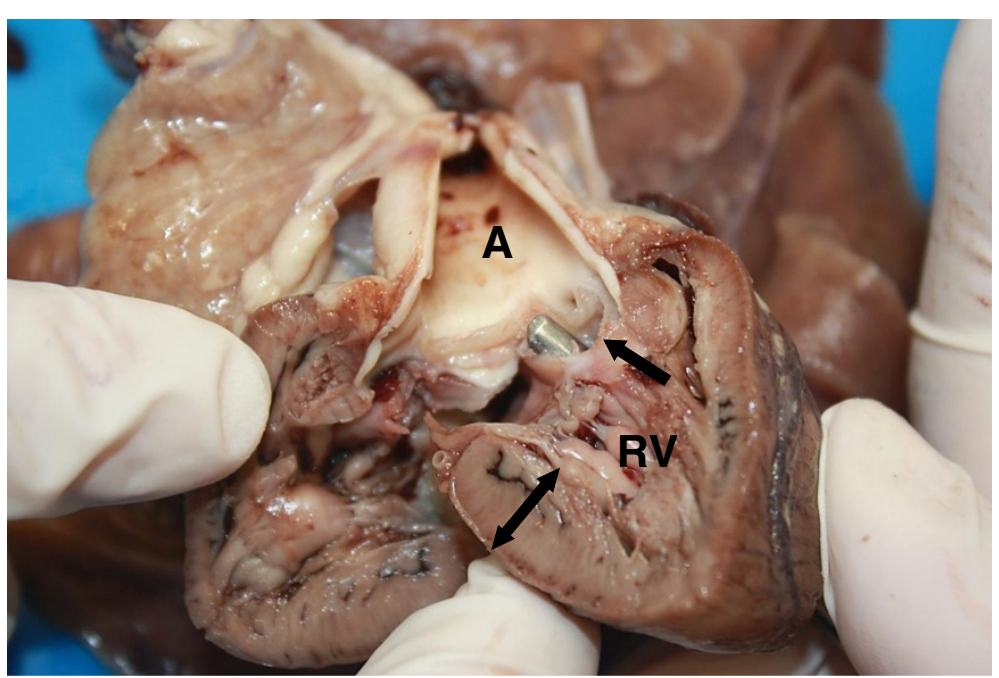

Figure 7 Sagittal section through the right ventricle (RV). An overriding aorta (A) communicating with the right ventricle (RV) and left ventricle through a subaortic ventricular septal defect (arrow and forceps). The right ventricular wall showed marked hypertrophy (double arrow). 


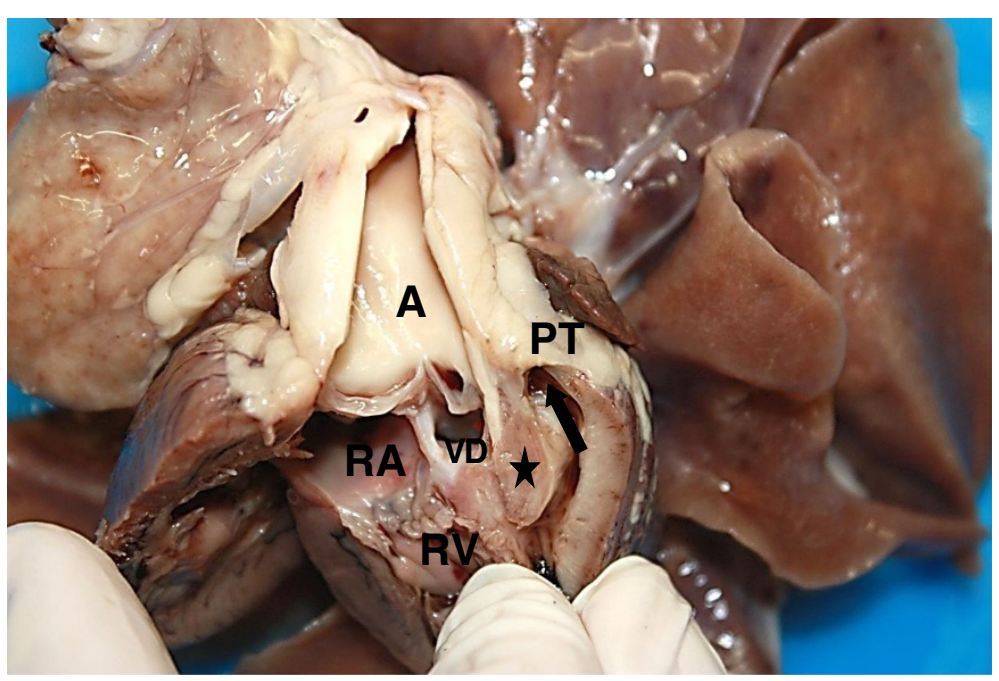

Figure 8 Sagittal section through the right ventricle (RV). A significantly hypoplastic pulmonary trunk (PT) demonstrates markedly reduced pulmonary arterial blood flow (arrow). Note the compressive effect (stenosis) of a hypertrophic proximal interventricular septum (star) on the pulmonary trunk (PT). Overriding aorta (A). Ventricular septal defect (VD). Right atrium (RA).

Bengal or white Tigers to date, abnormalities of the visual pathways have been associated with white Tigers [26]. The clinical presentation of the cub with cyanosis and tachypnoea was supported by the arterial blood gas that demonstrated severe hypoxaemia and concurrent mixed acid-base disturbance (metabolic acidosis and respiratory alkalosis) due to $\mathrm{CO}_{2}$ partial pressure lower than would be expected for pure compensation for the metabolic acidosis. The metabolic acidosis was most likely secondary to anaerobic cellular metabolism due to severe hypoxia, resulting in lactate accumulation. The lowerthan-expected $\mathrm{p}_{\mathrm{a}} \mathrm{CO}_{2}$ (considering the degree of peripheral cyanosis) was most likely a result of the severe tachypnoea due to the hypoxaemia, causing $\mathrm{CO}_{2}$ to be "blown-off" as well as only a mild right-to-left shunt seen on Doppler echocardiography. A larger shunt fraction/ pressure may have resulted in greater $\mathrm{p}_{\mathrm{a}} \mathrm{CO}_{2}$.

The radiological findings were supportive of PS with post-stenotic dilatation of the pulmonary artery but the pulmonary pattern was not typical for cardiogenic pulmonary oedema. In contrast to previous reports in dogs [12-14], diffuse cardiomegaly was not visualised in this Tiger. This may be due to the fact that the right-to-left ventricular septal defect shunting blood was directed into the subaortic region, thus minimising the effect of volume overload of the left heart while the moderate

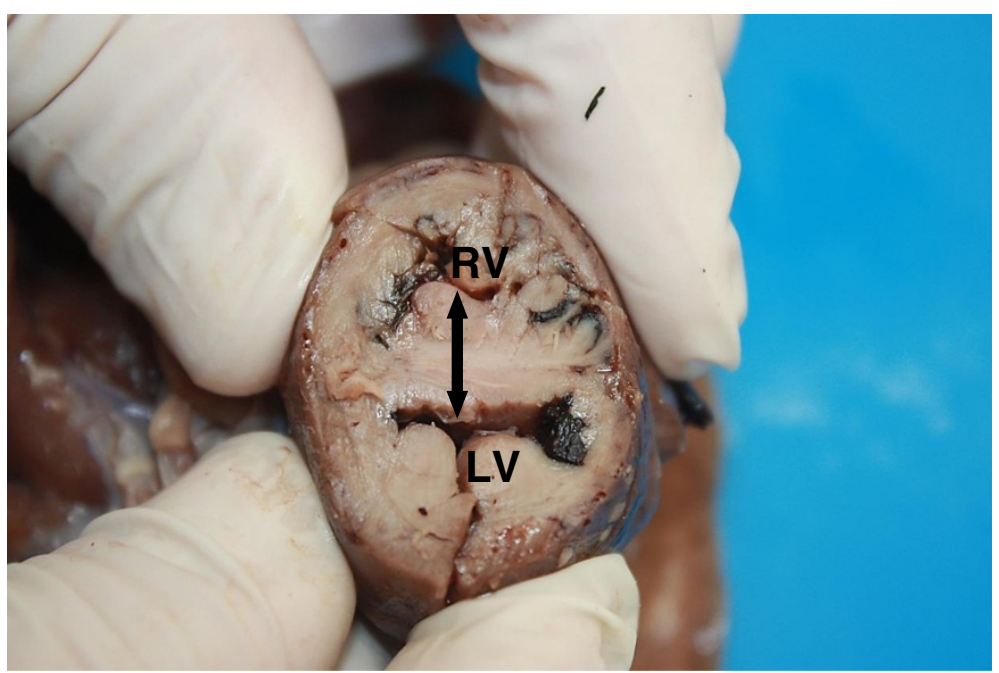

Figure 9 Cross section through the mid right \& left ventricular region (LV). The right ventricle (RV) shows severe concentric hypertrophy due to pulmonary arterial stenosis. Note the marked ventricular septal hypertrophy (double arrow). 


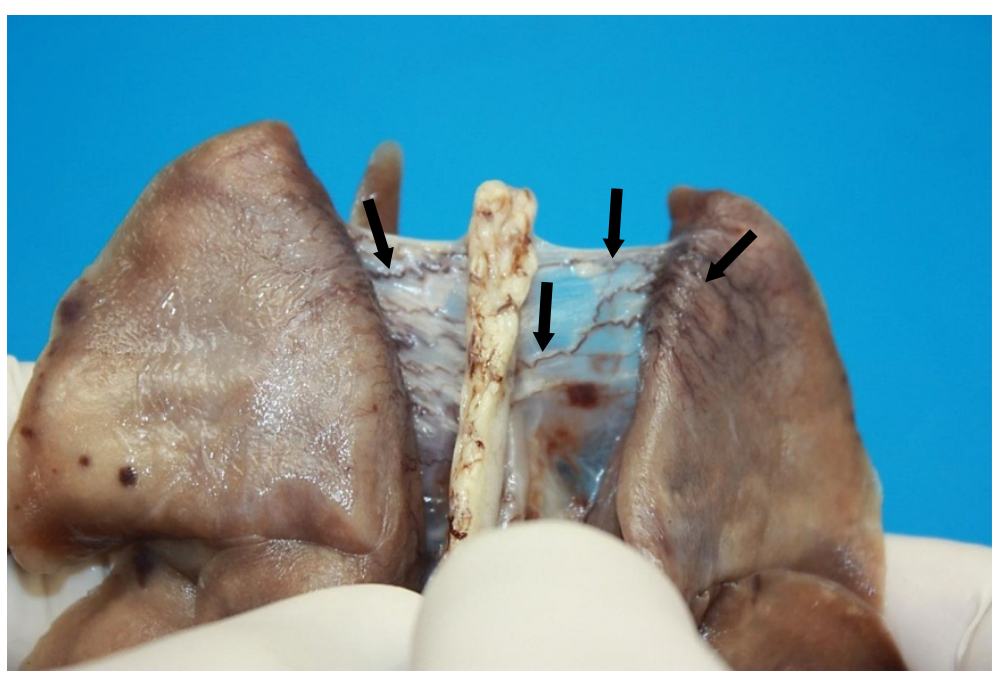

Figure 10 Dorsal view of the lungs and bisecting thoracic aorta. There are numerous prominent small tortuous thin walled blood filled vessels (veins) between the caudal pulmonary pleurae and periaortic mediastinal connective tissue (arrows). They originate as fine hair-like vessels in the pulmonary pleura and anastomose to form larger vessels towards the aortic adventitia where they drain into the azygos and costal veins (not in picture).

concentric hypertrophy of the right ventricle was not appreciable on radiographs.

The echocardiographic findings in this case were typical for a TOF and surprisingly the ASD was only detected during necropsy. Failure to identify the ASD on echocardiography was most likely due to the small size of the ASD while the absence of obvious shunting between the two chambers on colour flow Doppler was likely due to the equalisation of pressures between atria. The pulmonary outflow pressure in this cub was mildly increased compared to the previously reported value in the Korean Sapsaree dog also diagnosed with TOF and ASD [13]. The ventricular right-to-left shunt velocity measured in the Tiger cub may have included the left ventricular outflow tract due to the concomitant overriding aorta and could have resulted in a measured shunt velocity that is not a true reflection. Interestingly the right-to-left shunt velocity was of lower velocity than reported for the Korean Sapsaree dog [13], possibly related to the size of the VSD's. The authors recommend if the classic findings of a TOF are diagnosed, it is advised to thoroughly exclude the possibility of a PDA or ASD to ensure the diagnosis of a POF is not missed.

The necropsy findings were very similar to the previously described adult Siberian Tiger [18], except no endocardiosis of the mitral valve was present in this Tiger cub. The other significant difference was the presence of locally extensive pleural venous distension in the caudal thoracic peri-aortic mediastinum covering the area between the azygos vein and dorsocaudal pulmonary pleura in this cub. The PS resulted in progressive right ventricular hypertrophy which increased the degree of pulmonary truncal stenosis, resulting in diminishing pulmonary arterial pressure. Diminished pulmonary arterial pressure explains the pathological findings of pulmonary arteriolar collapse and hypoplasia associated with suspected increased flow resistance to the bronchial arterial supply of the lung. This would result in most of the bronchial arterial supply being shunted to the bronchial venous system (normally most of the bronchiolar arterial supply drains into the pulmonary arterial flow via anastomosis), causing distension of bronchial and pleural veins draining into the azygos and costal venous system. Coronary vein distension was most likely as a result of increased right atrial pressure subsequent to tricuspid valve insufficiency secondary to PS.

\section{Conclusions}

This report documented the first clinical case of TOF with ASD (a subclass of POF) in a Bengal Tiger with clinical and arterial blood gas signs of hypoxaemia, radiological and echocardiographic evidence of TOF and necropsy findings consistent with TOF with ASD. The reported findings may assist in the antemortem diagnosis of Tetralogy or Pentalogy of Fallot in other species.

\section{Abbreviations}

ASD: Atrial septal defect; $\mathrm{p}_{2} \mathrm{CO}_{2}$ : Arterial partial pressure of carbon dioxide; $\mathrm{P}_{\mathrm{a}} \mathrm{O}_{2}$ : Arterial partial pressure of oxygen; PDA: Patent ductus arteriosis; POF: Pentalogy of Fallot; PS: Pulmonic stenosis; TOF: Tetralogy of Fallot; VSD: Ventricular septal defect.

\section{Competing interests}

The authors declare that they have no competing interests. 


\section{Authors' contributions}

PP was the primary clinician on the case, collated all clinical and imaging information and is the primary author of the paper. CKL carried out the diagnostic imaging procedures and interpretation. JS performed the necropsy and histopathology examination and interpretation. All authors made intellectual contributions, reviewed and approved the final manuscript.

\section{Author details}

${ }^{1}$ Department of Companion Animal Clinical Studies, Faculty of Veterinary Science, University of Pretoria, Private Bag X04, Onderstepoort 0110, South Africa. ${ }^{2}$ Diagnostic Imaging Section, Department of Companion Animal Clinical Studies, Faculty of Veterinary Science, University of Pretoria, Private Bag X04, Onderstepoort 0110, South Africa. ${ }^{3}$ Current address: Department of Veterinary Clinical Sciences, College of Veterinary Medicine, Purdue University, West Lafayette, IN 47907-2026, USA. ${ }^{4}$ Section of Pathology, Department of Paraclinical Sciences, Faculty of Veterinary Science, University of Pretoria, Private Bag X04, Onderstepoort 0110, South Africa.

Received: 28 November 2013 Accepted: 27 February 2014

Published: 4 March 2014

\section{References}

1. Tidholm A: Retrospective study of congenital heart defects in 151 dogs. J Small Anim Pract 1997, 38:94-98.

2. Oliveira P, Domenech O, Silva J, Vannini S, Bussadori R, Bussadori C: Retrospective review of congenital heart disease in 976 dogs. J Vet Intern Med 2011, 25:477-483.

3. Bolton GR, Ettinger SJ, Liu SK: Tetralogy of Fallot in three cats. J Am Vet Med Assoc 1972, 160:1622-1631.

4. Kirby D, Gillick A: Polycythemia and Tetralogy of Fallot in a cat. Can Vet $J$ 1974, 15:114-119.

5. Fruganti A, Cerquetella M, Beribe F, Spaterna A, Tesei B: Clinic and ultrasonographic findings in a cat with Tetralogy of Fallot. Vet Res Commun 2004, 28:343-346.

6. Hall TL, Magdesian KG, Kittleson MD: Congenital cardiac defects in neonatal foals: 18 cases (1992-2007). J Vet Intern Med 2010, 24:206-212.

7. Mohamed T, Sato H, Kurosawa T, Oikawa S, Nakade T, Koiwa M: Tetralogy of Fallot in a calf: clinical, ultrasonographic, laboratory and postmortem findings. J Vet Med Sci 2004, 66:73-76.

8. Lacasta D, Ruiz S, Ramos JJ, Ferrer LM, Fernadez A, Gomez P: Tetralogy of Fallot in a three-month-old lamb: clinical, ultrasonographic and laboratory findings. Vet $\operatorname{Rec} 2011,169: 73$.

9. Wenger S, Gull J, Glaus T, Blumer S, Wimmershoff J, Kranjc A, Steinmetz H, Hatt JM: Fallot's Tetralogy in a European beaver (Castor fiber). J Zoo Wildlife Med 2010, 41:359-362.

10. Koie H, Abe Y, Sato T, Yamaoka A, Taira M, Nigi H: Tetralogy of Fallot in a Japanese macaque (Macaca fuscata). J Am Ass Lab Ani 2007, 46:66-67.

11. Agren E, Soderberg A, Morner T: Fallot's Tetralogy in a European brown bear (Ursus arctos). J Wildl Dis 2005, 41:825-828.

12. McEntee K, Snaps F, Clercx C, Henroteaux M, Dondelinger R: Clinical vignette [Tetralogy of Fallot associated with a patent ductus arteriosus in a German Shepherd dog]. J Vet Intern Med 1998, 12:53-55.

13. InChul $P$, HyeSun L, JongTaek K, JoonSeok L, SeungGon L, ChangBaig H: Pentalogy of Fallot in a Korean Sapsaree dog. J Vet Med Sci 2007, 69:73-76.

14. SeungKeun L, JinUng J, ChangBaig H: Pentalogy of Fallot with subaortic stenosis in a mixed dog. J Vet Clin 2009, 26:155-159.

15. Bayly WM, Reed SM, Leathers CW, Brown CM, Traub JL, Paradis MR, Palmer $\mathrm{GH}$ : Multiple congenital heart anomalies in five Arabian foals. J Am Vet Med Assoc 1982, 181:684-689.

16. Rahal C, Collatos C, Solano M, Bildfell R: Pentology of Fallot, renal infarction and renal abscess in a mare. J Equine Vet Sci 1997, 17:604-607.

17. Pielmeier R, Engelke E, Legler M, Haist V, Hopster-Iversen C, Distl O: Congenital cardiac anomalies (Pentalogy of Fallot) in a two year old ram with brachygnathia inferior [in German]. Berl Munch Tierarztl Wochenschr 2013, 126:256-263.

18. Scaglione FE, Tursi M, Chiappino L, Schroder C, Triberti O, Bollo E: Pentalogy of Fallot in a captive Siberian Tiger (Panthera tigris altaica). J Zoo Wildlife Med 2012, 43:931-933.

19. MacDonald KA: Congenital heart diseases of puppies and kittens. V Clin N Am - Small 2006, 36:503-531.
20. Eldadah ZA, Hamosh A, Biery NJ, Montgomery RA, Duke M, Elkins R, Dietz HC: Familial Tetralogy of Fallot caused by mutation in the jagged1 gene. Hum Mol Genet 2001, 10:163-169.

21. Goldmuntz E, Geiger E, Benson DW: NKX2.5 mutations in patients with Tetralogy of Fallot. Circulation 2001, 104:2565-2568.

22. Pizzuti A, Sarkozy A, Newton AL, Conti E, Flex E, Digilio MC, Amati F Gianni D, Tandoi C, Marino B, Crossley M, Dallapiccola B: Mutations of ZFPM2/FOG2 gene in sporadic cases of Tetralogy of Fallot. Hum Mutat 2003, 22:372-377.

23. Lambrechts D, Devriendt K, Driscoll DA, Goldmuntz E, Gewillig M, Vlietinck R, Collen D, Carmeliet P: Low expression VEGF haplotype increases the risk for Tetralogy of Fallot: a family based association study. J Med Genet 2005, 42:519-522.

24. Patterson DF: Genetic aspects of congenital heart disease in the dog. Gaines Dog Re Pro 1972, 4:7.

25. Patterson DF, Pyle RL, Mierop L, Melbin J, Olson M: Hereditary defects of the conotruncal septum in Keeshond dogs: pathologic and genetic studies. Am J Cardiol 1974, 34:187-205.

26. Guillery RW, Kaas JH: Genetic abnormality of the visual pathways in a "white" tiger. Science 1973, 180:1287-1289.

doi:10.1186/1751-0147-56-12

Cite this article as: Pazzi et al:: Tetralogy of Fallot and atrial septal defect in a white Bengal Tiger cub (Panthera tigris tigris). Acta Veterinaria Scandinavica 2014 56:12.

\section{Submit your next manuscript to BioMed Central and take full advantage of:}

- Convenient online submission

- Thorough peer review

- No space constraints or color figure charges

- Immediate publication on acceptance

- Inclusion in PubMed, CAS, Scopus and Google Scholar

- Research which is freely available for redistribution 